Pacific Journal of Mathematics

VARIOUS TYPES OF LOCAL HOMOGENEITY 


\section{VARIOUS TYPES OF LOCAL HOMOGENEITY}

\section{DORON RAVDIN}

In this paper some notions of local homogeneity for metric space are investigated. A theorem on convergence of a sequence of homeomorphisms to a homeomorphism is proved and applied i.e., to show that for every two countable and dense subsets $A$ and $B$ of the Hilbert space $l_{2}$ there exists a homeomorphism $H$ of $l_{2}$ onto itself such that $H(A)=B$.

Let $\left\{h_{n}\right\}_{n=1}^{\infty}$ be a sequence of homeomorphisms of a space $X$ onto itself and let

$$
H_{n}=h_{n} \circ h_{n-1} \circ \cdots \circ h_{1}
$$

denote their composition.

In this note conditions-similar to those obtained by J. L. Paul in [4]-are given under which $H=\lim _{n \rightarrow \infty} H_{n}$ exists and is a homeomorphism of $X$ onto itself. The obtained results are applied to investigate various types of local homogeneity and to prove that if $X=l_{2}$ is the Hilbert space then $X$ has the following property: For every two countable and dense subsets $A$ and $B$ of $X$ there exists a homeomorphism $H$ of $X$ onto itself such that $H(A)=B$.

A space $X$ having this property was called by R. B. Bennett countable dense homogeneous (see [1]).

A proof that the Euclidean $n$-space $E^{n}$ is countable dense homogeneous can be found in the book of W. Hurewicz and H. Wallmann "Dimension Theory" on p. 44.

In this paper the notion of countable dense homogeneity in the class of complete metric spaces is investigated and results-similar to those given by R. B. Bennett in [1] for locally compact spaces-are obtained.

In the sequel $X$ denotes a metric space with metric $\rho, B(x, r)$ the open ball with radius $r$ centered at $x, \delta(V)$-the diameter of a subset $V$ of $X$ and $\mathrm{nbd}$ stands for neighborhood. We also always assume that $\delta(X) \leqq 1$.

1. In this section conditions are given under which a sequence of homeomorphisms $H_{n}$ of $X$ onto itself converges to a homeomorphism $H$ of $X$ onto itself. Theorem 1 is a generalization of a similar theorem proved by J. L. Paul, (see [4]). We shall use the following two definitions:

Definition 1. A sequence $\left\{U_{n}\right\}_{n=1}^{\infty}$ of open subsets of $X$ is said to be proper if 


$$
U_{i} \cap U_{j} \neq \varnothing \Longrightarrow U_{i} \supset \bar{U}_{j} \text { for } i<j \text {. }
$$

Definition 2. A homeomorphism $h$ of $X$ onto itself will be called of type $(\xi, r, U)$ where $0<\xi<1,1 \leqq r$ are constants and $U$ is an open subset of $X$ if:

$$
\left.h\right|_{X \backslash V} \text { is the identity mapping }
$$

and

$$
\rho(h(x), h(y))>\xi[\rho(x, y)]^{r} \text { for all } x \neq y \text { in } X \text {. }
$$

THEOREM 1. Let $X$ be a complete metric space and $\left\{U_{n}\right\}_{n=1}^{\infty} a$ proper sequence. Let $\left\{h_{n}\right\}_{n=1}^{\infty}$ be a sequence of homeomorphisms of $X$ onto itself where $h_{n}$ is of type $\left(\xi_{n}, r_{n}, U_{n}\right)$. If

$$
\delta\left(U_{n}\right)<\xi_{n-1} \cdot \xi_{n-2}^{r_{n-1}} \cdots \cdots \xi_{1}^{r_{n-1} \cdots r_{2}} \cdot\left(\frac{1}{2^{n}}\right)^{r_{1} r_{2} \cdots r_{n}}
$$

then $H=\lim _{n \rightarrow \infty} H_{n}$ exists and is a homeomorphism of $X$ onto itself.

Proof. The proof being similar to Theorem 1 in [4] we shall confine ourselves to showing only that $H$ is continuous and one-to-one.

By (3), (4), and (5) $\rho\left(h_{n}(x), x\right)<1 / 2^{n}$. Hence $\rho\left(H_{n}(x), H_{n-1}(x)\right)<1 / 2^{n}$. The space $X$ being complete it follows that $H(x)=\lim _{n \rightarrow \infty} H_{n}(x)$ exists for all $x$ and that $H$ is continuous. To show that $H$ is one-to-one let $x \neq y$ be points of $X$. There are two cases:

Case 1. There exist integers $j(x)$ and $k(y)$ such that

$$
H_{l}(x)=H_{j(x)}(x) \text { for } l>j(x) \text { and } H_{m}(y)=H_{k(y)}(y) \text { for } m>k(y) \text {. }
$$

Then for $g=\max \{j(x), k(y)\}$ one has

$$
H(x)=H_{g}(x) \neq H_{g}(y)=H(y) .
$$

Case 2. For at least one of the points $x$ or $y$, (say $x$ ), there exists a sequence $m_{1}<m_{2}<\cdots$ such that $H_{m_{i-1}}(x) \in U_{m_{i}}$. Let $p=m_{i}$ be an integer of this sequence such that

$$
\left(\frac{1}{2^{p}}\right)^{r_{1} r_{2} \cdots r_{p-1}}<[\rho(x, y)]^{r_{1} r_{2} \cdots r_{p-1}}
$$

By (2) and (3) the points $H_{p-1}(x)$ and $H(x)$ belong to $U_{p}$.

By (4) we have

$$
\rho\left(H_{p-1}(x), H_{p-1}(y)\right)>\xi_{p-1} \xi_{p-2}^{r_{p-1}} \cdots \xi_{1}^{r_{2} r_{3} \cdots r_{p-1}}[\rho(x, y)]^{r_{1} r_{2} \cdots r_{p-1}} .
$$

Now by (5) and (6) $\delta\left(U_{p}\right)<\rho\left(H_{p-1}(x), H_{p-1}(y)\right)$. 
Therefore, $H_{p-1}(y) \notin U_{p-1}$, and thus also $H(y) \notin U_{p-1}$. Since $H(x) \in U_{p-1}$ it follows that $H(x) \neq H(y)$

REMARK 1. Theorem 1 remains true if the requirement that $X$ is complete is replaced by requiring the relative compactness of the $U_{i}$. The special case where $r_{n}=1(n=1,2 \cdots)$ is Theorem 1 of [4] and the proof is the same.

The following theorem shows a relation between the types (see Def. 2) of the homeomorphisms $\left\{h_{n}\right\}_{n=1}^{\infty}$ and of the limit $H=\lim _{n \rightarrow \infty} H_{n}$ of their superposition.

THEOREM 2. Let $\left\{U_{n}\right\}$ be a sequence of open subsets of $X$ such that $U_{n} \supset \bar{U}_{n+1}(n=1,2 \cdots)$ and let $\left\{h_{n}\right\}_{n=1}^{\infty}$ be a sequence of homeomorphisms of $X$ onto itself. If $h_{n}$ is of type $\left(1 / 2,1, U_{n}\right)$ and

$$
\delta\left(U_{n}\right)<\frac{1}{4^{n}}
$$

Then $H=\lim _{n \rightarrow \infty} H_{n}$ is a homeomorphism of $X$ onto itself of type $\left(1 / 4,2, U_{1}\right)$.

Proof. By Theorem 1, $H$ is a homeomorphism of $X$ onto itself and it suffices to show that

$$
\rho(H(x), H(y))>\frac{1}{4}[\rho(x, y)]^{2} \text { for all } x \neq y .
$$

Since by assumption $\delta(X) \leqq 1$ there exists an integer $n_{0} \geqq 1$ such that $(1 / 2)^{n_{0}}<\rho(x, y)=d \leqq(1 / 2)^{n_{0}-1}$. By (4) used for $\xi_{n}=1 / 2, r_{n}=1$ we have

$$
\rho\left(H_{n_{0}}(x), H_{n_{0}}(y)\right)>\left(\frac{1}{2}\right)^{n_{0}} d .
$$

Since by $(7) \delta\left(U_{n_{0}+1}\right)<1 / 4^{n_{0}+1}$, the points $H_{n_{0}}(x)$ and $H_{n_{0}}(y)$ are not both in $U_{n_{0}+1}$.

If both points are outside $U_{n_{0}+1}$ then by $U_{n} \supset \bar{U}_{n+1}$ and by (3) we have $H(x)=H_{n_{0}}(x)$ and $H(y)=H_{n_{0}}(y)$. Hence

$$
\rho(H(x), H(y))>\frac{1}{2^{n_{0}}} \cdot d>\frac{1}{4}[\rho(x, y)]^{2} .
$$

Thus we may assume that $H_{n_{0}}(x) \in U_{n_{0}+1}$ and $H_{n_{0}}(y) \notin U_{n_{0}+1}$. By (3) $\rho\left(H_{n_{0}}(x), H(x)\right)<\delta\left(U_{n_{0}+1}\right)<1 / 4^{n_{0}+1}$, whence

$$
\begin{aligned}
\rho(H(x), H(y))= & \rho\left(H(x), H_{n_{0}}(y)\right) \geqq \rho\left(H_{n_{0}}(x), H_{n_{0}}(y)\right)-\rho\left(H_{n_{0}}(x), H(x)\right) \\
& >\left(\frac{1}{2}\right)^{n 0} \cdot d-\left(\frac{1}{4}\right)^{n_{0}+1}>\frac{1}{4} d^{2} .
\end{aligned}
$$


REMARK 2. Clearly the types $\left(1 / 2,1, U_{n}\right)$ and $\left(1 / 4,2, U_{1}\right)$ can be replaced by other appropriate combinations.

2. In this section various notions of local homogeneity are defined. It is remarked that the Hilbert space $l_{2}$ is locally homogeneous of Type 1. It is then proved that for separable and complete metric spaces local homogeneity of a variable type implies countable dense homogeneity. Some problems and examples are also given.

Definition 3. Let $r \geqq 1$. A metric space $X$ will be called locally homogeneous of type $r$ if for every $X$ and every nbd. $U$ of $x$ there exists a nbd. $V$ of $x$ such that $V \subset U$ and such that for each two points $y_{1}$ and $y_{2}$ of $V$ there exists a homeomorphism $h$ of $X$ onto itself of type $(\xi, r, U)$ satisfying $h\left(y_{1}\right)=y_{2}$.

Let us note that if $X$ is locally homogeneous of type $r$ then $X$ is strongly locally homogeneous according to [1]. Furthermore, if $X$ is locally homogeneous of type $r$ then clearly $X$ is locally homogeneous of type $s$ for $s>r$ (we assume $\delta(X) \leqq 1$ ). The following example shows the converse does not hold.

ExAmple 1. Let $X$ be the subset of $E^{2}$ defined as follows: For any real number $r \geqq 1$ denote by $L_{n}$ the segment in $E^{2}$ whose endpoints are $(1 / n, 0)$ and $\left(1 / n,(1 / n)^{1 / r}\right)$, and by $M_{n}$ the segment in $E^{2}$ whose endpoints are $\left(1 / n,(1 / n)^{1 / r}\right)$ and $(1 /(n+1), 0)$, where $n=1,2 \cdots$. Define

$$
X=\bigcup_{n=1}^{\infty}\left(L_{n} \cup M_{n}\right) \cup\{(x, 0) \mid x \leqq 0 \quad \text { or } \quad x \geqq 1\} .
$$

Let $\tilde{d}$ be the metric on $X$ induced by $\widetilde{d}(x, y)=\min \{d(x, y), 1\}$ where $d$ is the usual Euclidean metric in $E^{2}$. Then $(X, \widetilde{d})$ is not locally homogeneous of type $r$ but is locally homogeneous of type $s$ for every $s>r$.

Definition 4. A space $X$ will be called locally homogeneous of variable type if for every $x \in X$ and every nbd $U$ of $x$ there exists a nbd. $V$ of $x$ such that $V \subset U$ and such that for each two points $y_{1}$ and $y_{2}$ of $V$ there exists a homeomorphism $h$ of $X$ onto itself of type $(\xi, r(x, U), U)$ satisfying $h\left(y_{1}\right)=y_{2} . \quad(r$ depends on $x$ and $U$.$) \quad A space$ which is locally homogeneous of strictly variable type is a space which is locally homogeneous of variable type but not of any fixed type $r$.

Clearly a space which is locally homogeneous of type $r$ is locally homogeneous of variable type. For an example of a space which is locally homogeneous of strictly variable type we give 
ExAMple 2. By modifying Example 1 we obtain an example of a locally homogeneous space of strictly variable type. Define

$$
X=\bigcup_{n, m=1}^{\infty}\left(L_{n, m} \cup M_{n, m}\right) \cup\{(x, 0) \mid x \leqq 0\}
$$

where $L_{n, m}$ is the segment in $E^{2}$ whose endpoints are $(1 / n+m-1,0)$ and $\left(1 / n+m-1,(1 / n+m-1)^{1 / m}\right)$ and $M_{n, m}$ is the segment in $E^{2}$ whose endpoints are $\left(1 / n+m-1,(1 / n+m-1)^{1 / m}\right)$ and $(1 /(n+1)+$ $m-1,0)$.

If $X$ is topologized by $\tilde{d}$ of Example 1 then $(X, \widetilde{d})$ is locally homogeneous of strictly variable type.

DeFinition 5. A separable metric space $X$ will be called (see [1]) countable dense homogeneous if for every two countable and dense subsets $A$ and $B$ of $X$ there exists a homeomorphism of $(X, A)$ onto $(X, B)$. The proof of the following theorem is not difficult and will be omitted.

Theorem 3. The Euclidean $n$-space $E^{n}$, the Hilbert space $l_{2}$ and the Cantor set $C$ are locally homogeneous of Type 1.

We now prove

Theorem 4. A complete separable metric space $X$ which is locally homogeneous of variable type is countable dense homogeneous.

Proof. Let $A=\left\{a_{i}\right\}_{i=1}^{\infty}$ and $B=\left\{b_{i}\right\}_{i=1}^{\infty}$ be two countable dense subsets of $X$. We shall construct by induction a sequence $\left\{h_{n}\right\}_{n=1}^{\infty}$ of homeomorphisms of $X$ onto itself such that $H=\lim _{n \rightarrow \infty} H_{n}$ is a homeomorphism of $X$ onto itself satisfying $H(A)=B$.

(a) Let $U=U_{1}=B\left(a_{1}, 1\right)$ and $V=V_{1} \subset U_{1}$ be the subset of $U$ given by Definition 4 . Let $b_{i_{0}}$ be an arbitrary point of $V_{1} \cap B$. By hypothesis there exists a homeomorphism $h_{1}$ of $X$ onto itself of type $\left(\xi_{1}, r_{1}, U_{1}\right)$ such that $h\left(a_{1}\right)=b_{i_{0}}$. Put $a_{1}^{*}=a_{1}$ and $b_{1}^{*}=b_{i_{0}}$.

Since $A \cup B$ is countable we can assume that $(A \cup B) \cap \mathrm{Bd}\left(U_{1}\right)=$ $\varnothing$.

(b) Define $b_{2}^{*}=b_{j}$ where $j$ is the first integer such that $b_{j} \in$ $B \backslash\left\{b_{1}^{*}\right\}$. Let $\varepsilon_{2}=\min \left\{\rho\left(b_{2}^{*}, a_{1}^{*}\right), \rho\left(b_{2}^{*} b_{1}^{*}\right), \rho\left(b_{2}^{*}, \mathrm{Bd} U_{1}\right), \xi_{1}\left(1 / 2^{2}\right)^{r_{1}}\right\}$.

Put $U=U_{2}=B\left(b_{2}^{*}, \varepsilon_{2} / 2\right)$ and let $V=V_{2} \subset U_{2}$ be the subset of $U_{2}$ given by Definition 4 . Let $h_{1}\left(a_{2}^{*}\right)$ be an arbitrary point of $h_{1}(A) \cap V_{2}$ (evidently $a_{2}^{*} \varepsilon A \backslash\left\{a_{1}^{*}\right\}$ ).

By hypothesis there exists a homeomorphism $h_{2}$ of type $\left(\xi_{2}, r_{2}, U_{2}\right)$ of $X$ onto itself such that $h_{2} \circ h_{1}\left(a_{2}^{*}\right)=b_{2}^{*}$. Again we can assume that $\left(h_{1}(A) \cup B\right) \cap \mathrm{Bd}\left(U_{2}\right)=\varnothing$. 
(c) Define $a_{3}^{*}=a_{i}$ where $i$ is the first integer such that $a_{i} \epsilon$ $A \backslash\left\{a_{1}^{*}, a_{2}^{*}\right\}$ and let

$$
\begin{aligned}
\varepsilon_{3}= & \min _{i \leqq 2}\left\{\rho\left(h_{2} \circ h_{1}\left(a_{3}^{*}\right), h_{2} \circ h_{1}\left(a_{i}^{*}\right)\right), \rho\left(h_{2} \circ h_{1}\left(a_{3}^{*}\right), \operatorname{Bd}\left(U_{i}\right)\right),\right. \\
& \left.\rho\left(h_{2} \circ h_{1}\left(a_{3}^{*}\right), b_{i}^{*}\right), \xi_{1} \xi_{2}\left(\frac{1}{2^{3}}\right)^{r_{1} r_{2}}\right\} .
\end{aligned}
$$

Put $U_{3}=B\left(h_{2} \circ h_{1}\left(a_{3}^{*}\right), \varepsilon_{3} / 2\right)$ and let $V_{3} \subset U_{3}$ be the subset of $U_{3}$ given by Definition 4. We can assume that $\left(h_{2}\left(h_{1}(A)\right) \cup B\right) \cap \mathrm{Bd}\left(U_{3}\right)=\varnothing$. Let $b_{3}^{*}$ be an arbitrary point of $B \cap V_{3}$ (evidently $b_{3}^{*} \in B \backslash\left\{b_{1}^{*}, b_{2}^{*}\right\}$ ). Again by hypothesis there exists a homeomorphism $h_{3}$ of $X$ onto itself of type $\left(\xi_{3}, r_{3}, U_{3}\right)$ such that $h_{3} \circ h_{2} \circ h_{1}\left(a_{3}^{*}\right)=b_{3}^{*}$.

(d) It should be clear how steps (b) and (c) can be repeated to obtain a sequence $\left\{h_{n}\right\}_{n=1}^{*}$ of homeomorphisms of $X$ onto itself satisfying the assumptions of Theorem 1. By Theorem $1 H=\lim _{n \rightarrow \infty} H_{n}$ is a homeomorphism of $X$ onto itself and clearly $H(A)=B$. Theorem 3 and Theorem 4 imply the following

Corollary 1. The Hilbert space $l_{2}$ is countable dense homogeneous. This result does not follow from [1].

The above concepts now lead to the following problems:

Problem 1. Let $r>s \geqq 1$ be fixed real numbers. Does there exist a metric space $(X, \rho)$ which is locally homogeneous of type $r$, and if $\rho_{1}$ is any metric on $X$ equivalent to $\rho$ then the space $\left(X, \rho_{1}\right)$ is not locally homogeneous of type $S$ ?

Problem 2. Does there exist a metric space $(X, \rho)$ which is locally homogeneous of strictly variable type for each metric $\rho_{1}$ equivalent to $\rho$ ?

Problem 3. Determine conditions which imply that a strongly locally homogeneous space is locally homogeneous of variable type.

The author wishes to thank the referee for his advice especially for supplying Definition 4, Example 2, and problem 2.

\section{REFERENCES}

1. R. B. Bennett, Countable dense homogeneous spaces, Fund. Math., 74 (1972), 189-194.

2. B. Fitzpatric, A note on countable dense homogeneity, Fund. Math., 75 (1972), 33-34.

3. W. Hurewicz and H. Wallmann, Dimension Theory, Princeton Univ. Press, 1959.

4. J. L. Paul, Sequences of homeomorphisms which converge to homeomorphisms, Pacific J. Math., 24 (1968), 143-152.

Received November 8, 1972 and in revised form April 8, 1973.

TeChNion, HaIfa, IsRael 


\section{PACIFIC JOURNAL OF MATHEMATICS}

\section{EDITORS}

RICHARD ARENS (Managing Editor)

University of California

Los Angeles, California 90024

\section{R. A. Beaumont \\ University of Washington \\ Seattle, Washington 98105}

\section{J. DugundjI*}

Department of Mathematics University of Southern California Los Angeles, California 90007

D. Gilbarg and J. Milgram

Stanford University

Stanford, California 94305

\section{ASSOCIATE EDITORS}
E. F. BeCKenBaCH
B. H. NeumanN
F. WOLF
K. YoSHIDA

\section{SUPPORTING INSTITUTIONS}

\author{
UNIVERSITY OF BRITISH COLUMBIA \\ CALIFORNIA INSTITUTE OF TECHNOLOGY \\ UNIVERSITY OF CALIFORNIA \\ MONTANA STATE UNIVERSITY \\ UNIVERSITY OF NEVADA \\ NEW MEXICO STATE UNIVERSITY \\ OREGON STATE UNIVERSITY \\ UNIVERSITY OF OREGON \\ OSAKA UNIVERSITY
}

\author{
UNIVERSITY OF SOUTHERN CALIFORNIA \\ STANFORD UNIVERSITY \\ UNIVERSITY OF TOKYO \\ UNIVERSITY OF UTAH \\ WASHINGTON STATE UNIVERSITY \\ UNIVERSITY OF WASHINGTON

$* * *$
$*$
AMERICAN MATHEMATICAL SOCIETY
NAVAL WEAPONS CENTER

The Supporting Institutions listed above contribute to the cost of publication of this Journal, but they are not owners or publishers and have no responsibility for its content or policies.

Mathematical papers intended for publication in the Pacific Journal of Mathematics should be in typed form or offset-reproduced, (not dittoed), double spaced with large margins. Underline Greek letters in red, German in green, and script in blue. The first paragraph or two must be capable of being used separately as a synopsis of the entire paper. Items of the bibliography should not be cited there unless absolutely necessary, in which case they must be identified by author and Journal, rather than by item number. Manuscripts, in duplicate if possible, may be sent to any one of the four editors. Please classify according to the scheme of Math. Rev. Index to Vol. 39. All other communications to the editors should be addressed to the managing editor, or Elaine Barth, University of California, Los Angeles, California, 90024.

100 reprints are provided free for each article, only if page charges have been substantially paid. Additional copies may be obtained at cost in multiples of 50 .

The Pacific Journal of Mathematics is issued monthly as of January 1966. Regular subscription rate: $\$ 60.00$ a year (6 Vols., 12 issues). Special rate: $\$ 30.00$ a year to individual members of supporting institutions.

Subscriptions, orders for back numbers, and changes of address should be sent to Pacific Journal of Mathematics, 103 Highland Boulevard, Berkeley, California, 94708.

PUBLISHED BY PACIFIC JOURNAL OF MATHEMATICS, A NON-PROFIT CORPORATION

Printed at Kokusai Bunken Insatsusha (International Academic Printing Co., Ltd.), 270, 3-chome Totsuka-cho, Shinjuku-ku, Tokyo 160, Japan

* C. R. DePrima California Institute of Technology, Pasadena, CA 91109, will replace J. Dugundji until August 1974. 


\section{Pacific Journal of Mathematics}

Vol. 50, No. $2 \quad$ October, 1974

Mustafa Agah Akcoglu, John Philip Huneke and Hermann Rost, A counter example to the Blum Hanson theorem in general spaces .............

Huzihiro Araki, Some properties of modular conjugation operator of von

Neumann algebras and a non-commutative Radon-Nikodym theorem

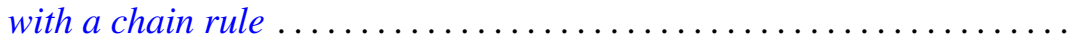

E. F. Beckenbach, Fook H. Eng and Richard Edward Tafel, Global properties of rational and logarithmico-rational minimal surfaces .....

David W. Boyd, A new class of infinite sphere packings ............. 383

K. G. Choo, Whitehead Groups of twisted free associative algebras ........

Charles Kam-Tai Chui and Milton N. Parnes, Limit sets of power series

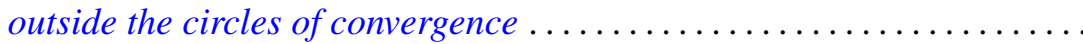

Allan Clark and John Harwood Ewing, The realization of polynomial

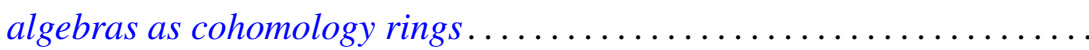

Dennis Garbanati, Classes of circulants over the p-adic and rational

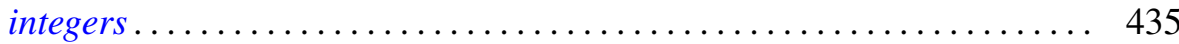

Arjun K. Gupta, On a "square" functional equation ................... 449

David James Hallenbeck and Thomas Harold MacGregor, Subordination and extreme-point theory ............................. 455

Douglas Harris, The local compactness of $v X \ldots \ldots . . . . . . . . . . . .4469$

William Emery Haver, Monotone mappings of a two-disk onto itself which fix the disk's boundary can be canonically approximated by homeomorphisms .................................. 477

Norman Peter Herzberg, On a problem of Hurwitz .................. 485

Chin-Shui Hsu, A class of Abelian groups closed under direct limits and subgroups formation ............................... 495

Bjarni Jónsson and Thomas Paul Whaley, Congruence relations and multiplicity types of algebras.....................

Lowell Duane Loveland, Vertically countable spheres and their wild sets.

Nimrod Megiddo, Kernels of compound games with simple components ....

Russell L. Merris, An identity for matrix functions ........ . .

E. O. Milton, Fourier transforms of odd and even tempered distributions ...

Dix Hayes Pettey, One-one-mappings onto locally connected generalized continua

Mark Bernard Ramras, Orders with finite global dimension

Doron Ravdin, Various types of local homogeneity. .

George Michael Reed, On metrizability of complete Moore spaces ...

Charles Small, Normal bases for quadratic extensions ..

Philip C. Tonne, Polynomials and Hausdorff matrices.... . . 